OPEN ACCESS

Edited by:

Jasmeen S. Merzaban, King Abdullah University of Science and Technology, Saudi Arabia

Reviewed by:

Rashmin C. Savani, University of Texas Southwestern Medical Center, United States Vincent Charles Hascall, Cleveland Clinic Lerner College of Medicine, United States

*Correspondence: Pauline Johnson pauline@mail.ubc.ca

Specialty section

This article was submitted to

Molecular Innate Immunity,

a section of the journal

Frontiers in Immunology

Received: 17 August 2018 Accepted: 12 November 2018 Published: 29 November 2018

Citation:

Johnson P. Arif AA, Lee-Sayer SSM and Dong $Y$ (2018) Hyaluronan and lts Interactions With Immune Cells in the Healthy and Inflamed Lung. Front. Immunol. 9:2787. doi: 10.3389/fimmu.2018.02787

\section{Hyaluronan and Its Interactions With Immune Cells in the Healthy and Inflamed Lung}

\author{
Pauline Johnson ${ }^{1 *}$, Arif A. Arif ${ }^{1}$, Sally S. M. Lee-Sayer ${ }^{1}$ and Yifei Dong ${ }^{2}$ \\ ${ }^{1}$ Department of Microbiology and Immunology, Life Sciences Institute, University of British Columbia, Vancouver, BC, \\ Canada, ${ }^{2}$ Department of Clinical Neurosciences, University of Calgary, Calgary, AB, Canada
}

Hyaluronan is a hygroscopic glycosaminoglycan that contributes to both extracellular and pericellular matrices. While the production of hyaluronan is essential for mammalian development, less is known about its interaction and function with immune cells. Here we review what is known about hyaluronan in the lung and how it impacts immune cells, both at homeostasis and during lung inflammation and fibrosis. In the healthy lung, alveolar macrophages provide the first line of defense and play important roles in immunosurveillance and lipid surfactant homeostasis. Alveolar macrophages are surrounded by a coat of hyaluronan that is bound by CD44, a major hyaluronan receptor on immune cells, and this interaction contributes to their survival and the maintenance of normal alveolar macrophage numbers. Alveolar macrophages are conditioned by the alveolar environment to be immunosuppressive, and can phagocytose particulates without alerting an immune response. However, during acute lung infection or injury, an inflammatory immune response is triggered. Hyaluronan levels in the lung are rapidly increased and peak with maximum leukocyte infiltration, suggesting a role for hyaluronan in facilitating leukocyte access to the injury site. Hyaluronan can also be bound by hyaladherins (hyaluronan binding proteins), which create a provisional matrix to facilitate tissue repair. During the subsequent remodeling process hyaluronan concentrations decline and levels return to baseline as homeostasis is restored. In chronic lung diseases, the inflammatory and/or repair phases persist, leading to sustained high levels of hyaluronan, accumulation of associated immune cells and an inability to resolve the inflammatory response.

Keywords: hyaluronan, inflammation, fibrosis, macrophages, lung, wound healing, extracellular matrix

\section{HYALURONAN IN THE HEALTHY LUNG}

\section{Hyaluronan (HA) in Lung Development}

$\mathrm{HA}$ is a high molecular mass glycosaminoglycan ( $>1 \mathrm{MDa})$ composed of repeating disaccharide units of D-glucuronic acid and $\mathrm{N}$-acetyl glucosamine (1). During fetal development of the lung, HA is present in the interstitium (2) and the alveolar space is filled with amniotic fluid that is rich in HA and hyaladherins that possess anti-inflammatory and wound healing properties $(3,4)$. During this time, fetal monocytes populate the mouse lung where they differentiate into CD11 $\mathrm{b}^{+} \mathrm{CD} 11 \mathrm{c}^{\text {lo }}$ Siglec $\mathrm{F}^{\mathrm{lo}}$ pre-alveolar macrophages (pre-AMs) (5-7). At birth, air fills the lungs, and pre-AMs develop into functional AMs $\left(\mathrm{CD} 11 \mathrm{c}^{+}\right.$Siglec $\left.\mathrm{F}^{\text {hi }} \mathrm{CD} 11 \mathrm{~b}^{-}\right)$, coinciding with the decrease in HA levels in the lung (7). AMs express high levels of CD44, a cell surface receptor for HA that is required for HA uptake in vitro $(8,9)$, and AMs are responsible for reducing HA levels in vivo (2). 


\section{HA Expression in Healthy Lung Tissue}

In the uninflamed lung, HA, detected by biotinylated HA binding protein (HABP), is bound to the surface of AMs in the alveolar space [Figure 1 and (10-12)]. HA is also in the basement membrane region of bronchial and bronchiolar epithelium, and in the perivascular region (prominent in the adventitia) of large blood vessels [Figure 2 and $(2,10-12)$ ]. In lung sections, HA is not apparent in the alveolar interstitium or on alveolar epithelium (10). CD44 is present on the basolateral surface of bronchial epithelium (10), consistent with the localization of HA to the basement membrane.

\section{HA Turnover in the Alveolar Space}

In general, HA turns over very rapidly compared to other extracellular matrix components: approximately a third of the body's HA turns over daily (15). HA is produced by HA synthases (HAS1-3) at the plasma membrane that extrude HA into the extracellular space (16). Type II alveolar epithelial cells (AECs) express HAS2 and surface HA (17). HA is loosely attached and shed from the apical surface of primary AEC cultures, and can be observed above the airway epithelium (18), although this is not

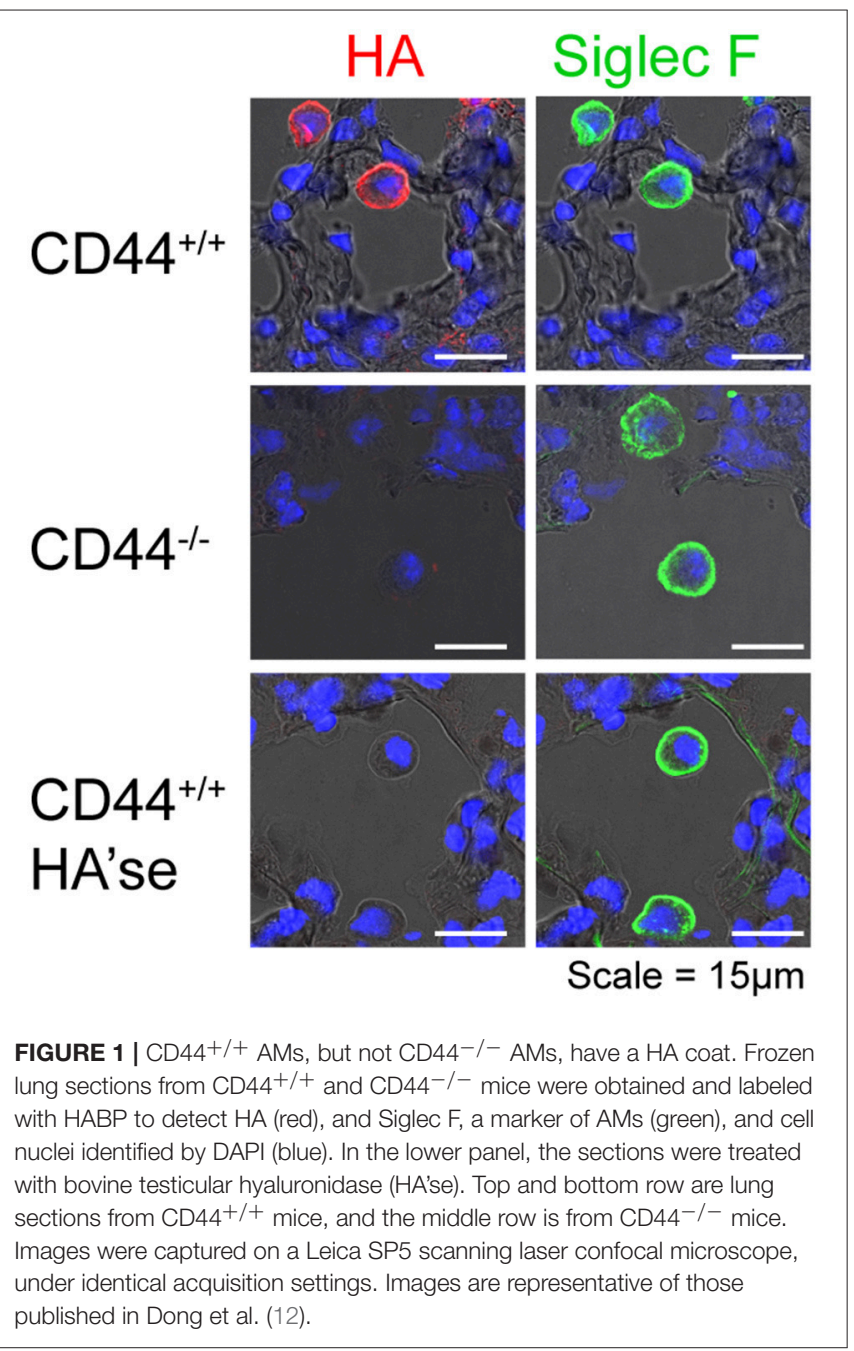

always the case $(10,12)$. This suggests that HA can be released into the alveolar fluid above the AECs. Since HA levels are low in bronchoalveolar lavage fluid (BALF) from healthy animals (19), HA must be turned over, possibly by AMs, which takeup and degrade $\mathrm{HA}$ in vitro $(8,9)$ and bind $\mathrm{HA}$ in vivo $(12)$. Clearance of HA involves its degradation into smaller fragments by hyaluronidases such as Hyal $2(20,21)$, TMEM2 (22), and possibly KIAA1199 (23) at the cell surface. These fragments are then internalized by receptors such as CD44 and HARE/Stabilin2 and taken to the lysosome where they are degraded by Hyal 1 $(16,24,25)$.

\section{HA Binding to AMs Promotes Their Survival and Maintenance}

The ability of CD44 to bind HA is highly regulated in cells (26-30). AMs express a form of CD44 that constitutively binds HA $(8,12,31)$. In contrast, CD44 on unactivated monocytes, macrophage colony stimulating factor-derived macrophages, and peritoneal macrophages, do not bind fluoresceinated HA (FL-HA) $(31,32)$. However, when peritoneal macrophages are introduced into the lung airways, they gain the ability to bind FLHA (12), highlighting the influence of the alveolar environment on HA binding. Granulocyte-macrophage colony stimulating factor (GM-CSF or CSF-2) and PPAR $\gamma$ are both important in the alveolar space for AM development and maintenance $(6,33)$ and treatment of bone marrow-derived macrophages with GM-CSF and a PPAR $\gamma$ agonist, rosiglitazone, induces CD44-dependent HA binding (12), implicating these factors in regulating HA binding by AMs in the alveolar space.

AMs possess a HA coat that is anchored to its surface by CD44, and is absent in CD44-/- AMs, Figure 1 and (12). The HA coat was unexpected, given the AMs ability to take-up and degrade HA $(8,9)$. Although high molecular mass HA (HMW$\mathrm{HA},>1 \mathrm{MDa}$ ) predominates in uninflamed lung tissue (19), the size and origin of HA in the AM coat is not known. What is known is that this HA coat promotes the survival of AMs, and its removal by hyaluronidases induces apoptosis (12). CD44-/AMs are more susceptible to apoptosis and mice lacking CD44 have reduced numbers of AMs in the lung (12). The engagement of HA by CD44 is required for optimal AM survival in vivo, as its disruption with an HA blocking CD44 antibody leads to reduced numbers of AMs (12).

\section{Effect of Type II AEC Generated HA}

AMs reside in the alveolar space, above the AEC layer, in the fluid surfactant layer, where some AMs closely associate with AECs $(10,34)$. They form intimate connexin-43-dependent gapjunction interactions which can modulate inflammation (34). CD200-CD200R and $\alpha v \beta 6$-tumor growth factor beta (TGF $\beta$ )TGF $\beta R$ interactions further support an association between these cells, which acts to limit AM activation $(13,35)$. Although type II AECs express HAS2 (17), it is unclear if type I AECs, which form the majority of the alveolar epithelial surface, also synthesize HA. At homeostasis, HA produced by type II AECs may be bound and/or taken up by AMs, keeping HA levels low in the surfactant layer. Alternatively, HA binding by AMs may strengthen their immunosuppressive connection with AECs, or 

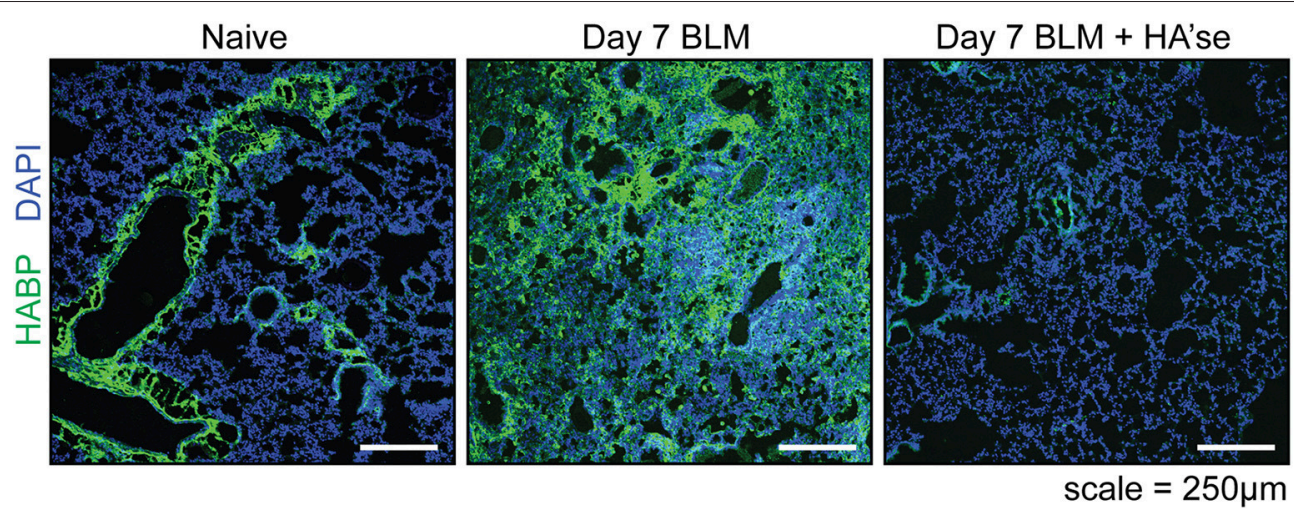

FIGURE 2 | Hyaluronan in the healthy and inflamed mouse lung. Frozen lung sections from CD44 $+/+$ mice were labeled with $\mathrm{HABP}$ (green) to detect $\mathrm{HA}$, and stained with DAPI (blue) to label cell nuclei. On the left is a representative image of the healthy (naïve) lung where HA is present on the major bronchioles and blood vessels, with little labeling in the interstitium. The middle panel shows HA present in the lung 7 days after bleomycin induced lung inflammation (Day 7 BLM). The panel on the right is a control, showing a lung section from day $7 \mathrm{BLM}$, after treatment with hyaluronidase. All images were captured using an Olympus FV1000 scanning laser confocal microscope under identical acquisition settings. These images are similar to data described in Cheng et al. (11), Hussell and Bell (13), and Sahu and Lynn (14).

independently promote immunosuppressive behavior, as HMWHA has been shown to limit activation in other cells (36, 37). HAS2 overexpression in type II AECs protects these cells against bleomycin-induced apoptosis, as does HMW-HA (38). Conversely, loss of HAS2 expression leads to their decreased renewal capacity in vitro (17) supporting the idea that, like AMs, HA promotes the survival/self-renewal ability of type II AECs. HMW-HA also supports the survival/ self-renewal capacity of stem cells [reviewed in (39-41)], suggesting a common function for HMW-HA in promoting the survival of cells capable of self-renewal.

\section{HA IN THE INFLAMED LUNG}

\section{HA Levels Are Elevated in Lung Disease}

$\mathrm{HA}$ is upregulated during tissue inflammation in many diseases and across many tissues $(42,43)$. The upregulation of HA is a general characteristic of inflammation, occurring in a broad repertoire of inflammatory and infectious conditions irrespective of the type of stimuli or the type of immune response generated (inflammatory: type 1, or allergic, fibrotic: type 2), and has been the subject of many excellent reviews (43-47).

In the lung, the concentration of $\mathrm{HA}$ is elevated in the BALF of patients suffering from asthma (14), chronic obstructive pulmonary disease (48), interstitial pulmonary fibrosis (49), and other lung diseases [reviewed in $(43,44)]$. In animal models, HA is upregulated in the bleomycin model of sterile injury $(19,50)$, asthma (ova and cockroach allergen) $(11,51)$, ozone-induced airway hyperreactivity (52), LPS-induced acute lung injury, and Escherichia coli (53), Klebsiella pneumoniae (54), or Influenza infection (55).

\section{Hyaladherin Expression Is Increased Upon Inflammation}

In addition to HA, several hyaladherins are upregulated upon lung inflammation [reviewed in $(46,56-60)]$. These include versican, the heavy chain (HC) of the inter-alpha-trypsin inhibitor $(\mathrm{I} \alpha \mathrm{I})$, link protein, tumor necrosis factor stimulated gene 6 (TSG-6), pentraxin-3, and aggrecan, which can bind to, and modify, the HA glycocalyx. TSG-6 is an enzyme that catalyzes the covalent transfer of the HC of I $\alpha$ I to HA (59). TSG-6 can also independently bind and crosslink HA to form a more compact matrix (61) that has increased binding to CD44 (62). In intestinal inflammation, smooth muscle cells generate distinctive $\mathrm{HA}$ cables that are modified by $\mathrm{HC}$ and adhesive for platelets, key cells in the wound healing process (63). Activated platelets express Hyal 2 (64) and can degrade HA cables down to $20 \mathrm{kDa}$ fragments, but lack Hyal 1 which would allow complete digestion (65).

\section{HA Levels Correlate With Inflammatory Infiltrate}

Animal models of lung infection, injury, and inflammation allow a closer analysis of the changes that occur to HA during the inflammatory response. In models of acute and chronic asthma, HAS1 and 2 are rapidly upregulated in the lung only a few hours after re-exposure to allergen, while Hyal 1 and 2 decrease over time, leading to the accumulation of HA that is maximal after 6 days and is maintained with continued chronic stimulation (11). Inflammatory stimuli also induce TSG6 expression, which maintains HA deposition and eosinophil recruitment (66). Eventually, HA levels return to baseline after about 8 weeks (11).

In a model of acute sterile lung inflammation, a single dose of bleomycin induces HA expression in the lung tissue (67) and Figure 2 (Day 7 BLM), which, together with leukocyte infiltration, peaks at day $7(19,50)$. In inflammation, HA has a smaller average molecular mass of $0.5 \mathrm{MDa}$ compared to 1.5 $\mathrm{MDa}$ in naïve lungs (19). Detection of HA decreases as collagen deposition increases in the remodeling phase (day 14 to past 21) $(19,47)$. Final resolution of the response involves the return of HA to baseline levels which occurs around 5 weeks (50), 
together with the removal of collagen, myofibroblasts, fibrotic macrophages, and the restoration of lung epithelium by type II AECs (24).

In the absence of CD44, HA levels continue to increase after bleomycin treatment and the severity of inflammation increases. HA sizes become smaller and more heterogeneous, ranging from 0.02 to $2 \mathrm{MDa}$ (19). HA levels and the leukocyte infiltrate are reduced if $\mathrm{CD} 44^{+/+}$bone marrow cells are transplanted into irradiated CD44 ${ }^{-/}$mice, implicating CD $44^{+/+}$leukocytes (potentially macrophages) in the uptake and clearance of HA.

HMMR/RHAMM has been described as a receptor for HAmediated motility and as a intracellular centrosomal protein involved in spindle orientation and integrity that is upregulated during the cell cycle (68). Genetic deletion of HMMR at exon 2 is lethal in mice (69) whereas deletion of exons 8 or 10 leads to their survival $(70,71)$. The exon 8 targeted mice have reduced $\mathrm{HA}$ and lung inflammation and less inflammatory macrophages in response to bleomycin, whereas mice overexpressing RHAMM in scavenger receptor A positive macrophages show the opposite (72). Thus the effects of RHAMM are distinct from that of CD44. RHAMM affects both macrophage proliferation and motility in vitro (72), but further work is required to determine its mechanism in lung inflammation.

Influenza virus causes severe damage in the lung that is repaired for months after the virus has been cleared (35). During this recovery period, the lung is more susceptible to bacterial infections. Recent work found that HA levels remain high in the lung tissue due to elevated HAS2 expression in epithelial, endothelial, and fibroblast cells (55). TSG-6 levels are also elevated and this generates a HC-modified HA matrix (55). Interestingly, a single dose of hyaluronidase at day 6 after influenza infection reduces the HA content in the lung, reduces the number of $\mathrm{F} 4 / 80^{+} \mathrm{CD} 11 \mathrm{~b}^{+} \mathrm{CD} 11 \mathrm{c}^{\text {lo }}$ macrophages and improves lung function at day 16 (55).

These models of lung inflammation show that HA levels increase with inflammation, suggesting a role for $\mathrm{HA}$ in supporting the leukocyte infiltrate. HA is hygroscopic and has been linked with edema formation (73), which would allow easier movement of leukocytes in the damaged tissue. In the bleomycin model, HA levels decrease after the peak of inflammation, whereas in the asthma and influenza models, increased HA levels persist. Only after remodeling and completion of the repair process do HA levels return to baseline levels.

\section{HA Fragments in Inflammation: Present Challenges}

It is important to keep in mind that both pericellular and extracellular HA matrices are thought to turnover frequently. This means that HA is continually synthesized and degraded, and during inflammation, increased synthesis leads to the accumulation of HA. The size of this HA is more heterogenous and HA fragments (varying from small oligosaccharides to 0.5 $\mathrm{MDa}$ ) are considered damage-associated molecular patterns that stimulate inflammatory responses [reviewed in (26), (36), (38), (42), (43)]. However, this has recently been challenged by studies showing that some $\mathrm{HA}$ and hyaluronidase preparations are contaminated with endotoxin $(74,75)$. This, together with the absence of evidence showing direct binding of HA fragments to TLRs, has questioned whether HA fragments directly promote inflammation. An alternative explanation is that smaller sized HA fragments displace HMW-HA bound to CD44, and disrupt its protective, immunosuppressive effect (76). In some cells, HMW-HA inhibits NF-кb signaling (77), and so its displacement by HA fragments would result in a proinflammatory NF-кb response. Another explanation for the variation in results seen with different sized HA fragments may arise from the use of polydisperse HA where a range of HA sizes within a single preparation compete for receptors to initiate the inflammatory signal (78). There is some evidence that HARE/Stabilin-2 responds to specific sizes of HA (79). Why would HA fragments as large as $200 \mathrm{kDa}$ be seen differently from $1 \mathrm{MDa} \mathrm{HA}$, when HA receptors, such as CD44, recognize just a few sugar units (80)? The answer may lie in the ability of different forms of HA to cluster HA receptors and thereby influence the signal delivered. Recent work shows that HA undergoes a transition from a random coil to a rod shape at around $200 \mathrm{kDa}$, suggesting that these forms could differentially impact HA receptor clustering and signaling (81). In support of this idea, TSG-6-crosslinked HA creates a more compact matrix (61) that is more efficiently recognized by the HA receptors, CD44 (62) and Lyve-1 (82). HC-modified HA forms cables (83) that also alter how HA is perceived by the cell (63). Clearly, more work is needed to understand the contribution of HA fragments and hyaladherins in the inflammatory response.

\section{HA Binding Immune Cells in Lung Inflammation and Repair}

In a type I inflammatory response, neutrophils and inflammatory monocytes are recruited to the site of infection, where they contribute to the proinflammatory environment and respond to the threat. Neither of these cell types bind appreciable levels of FL-HA (26). In a type 2 allergic response, eosinophils are recruited (11) and these cells bind low levels of FL-HA (84). In animal models of acute and chronic asthma, eosinophils are present in HA-rich areas of the inflamed lung (11). Once in the inflamed lung, inflammatory monocytes differentiate into macrophages and become F4/80 ${ }^{+} \mathrm{CD}_{11} \mathrm{~b}^{+} \mathrm{CD} 11 \mathrm{c}^{+}$Siglec $\mathrm{F}^{\mathrm{lo}}$ during the repair phase $(12,85)$. These macrophages bind FLHA (12), produce TGF $\beta$ and drive bleomycin-induced fibrosis (85). In a mouse model of allergic asthma, $\mathrm{F} 4 / 80^{+}$macrophages are found with HA and versican in the subepithelial region of the lung (86). Thus, HA binding may provide one possible means of bringing immune cells such as eosinophils and fibrotic macrophages into close proximity with the HA-producing myofibroblasts involved in repair.

\section{HA Producing Myofibroblasts in Lung Repair}

During the course of lung inflammation, the cells responsible for the increase in HA synthesis have not been clearly defined. However, individually, fibroblasts, myofibroblasts, endothelial cells, smooth muscle cells, and type II AECs can all produce 
pericellular HA coats in response to inflammatory or reparative stimuli $(24,42,46)$. Myofibroblasts are major HA-producing cells that have key roles in wound repair, collagen deposition, and fibrosis (24). TGF $\beta$ induces the differentiation of fibroblasts into smooth muscle actin positive myofibroblasts and enhances their production of pericellular HA (87). HA further promotes their differentiation and maintenance $(85,88,89)$. TGF $\beta$ induces HAS1 and 2 expression in fibroblasts $(90,91)$ and reduces Hyal 1 and 2 expression (92), and this HA is required for TGF $\beta$-induced fibroblast proliferation by providing a late pERK signal $(93,94)$. TGF $\beta$ also induces TSG-6 which generates HC modified HA cables that facilitate myofibroblast differentiation $(88,89,95)$. Overexpression of HAS2 in lung myofibroblasts leads to a severe fibrotic response and invasive fibroblast phenotype (96), while the deletion of HAS2 in fibroblasts increases cellular senescence in a mouse model of pulmonary fibrosis (97). Thus, pericellular HA is intimately linked to the fibrotic/repair function of myofibroblasts.

\section{Type II AECs in Lung Inflammation and Repair}

In the repair phase, damaged type I AECs are replaced by the differentiation of type II AECs, which have stem cell-like properties (98). Both the loss and overexpression of HAS2 in type II AECs have significant effects on epithelial cell repair in response to bleomycin, with $\mathrm{HA}$ protecting against epithelial damage and apoptosis, and the loss of HA impairing AEC renewal and leading to severe fibrosis $(17,38)$. Likewise, type II AECs isolated from patients with severe pulmonary fibrosis have reduced levels of surface HA (17). Thus, HA has a protective effect on type II AECs.

\section{AMs in Lung Inflammation and Repair}

Lung inflammation results in the depletion of tissue resident, fetal monocyte-derived AMs, with the extent of their loss proportional to the severity of the insult $[(12,33,85,99,100)$ and Dong et al., unpublished data]. The cause of this loss is not understood, but it has been suggested that macrophage necrosis triggers the ensuing inflammatory response (101-103). Maximal loss of AMs occurs at the peak of leukocyte infiltration and HA accumulation, after which the AMs increase in numbers, due in large part to self-renewal $(12,33,100)$. Since AMs are implicated in HA uptake and degradation $(8,9)$, it is possible that their loss could contribute to the increased levels of HA observed upon inflammation. However, this remains to be determined. Whether

\section{REFERENCES}

1. Laurent TC, Fraser JRE. Hyaluronan. FASEB J (1992) 6:2397-404.

2. Underhill CB, Nguyen HA, Shizari M, Culty M. CD44 positive macrophages take up hyaluronan during lung development. Dev Biol. (1993) 155:324-36. doi: 10.1006/dbio.1993.1032

3. He H, Li W, Tseng DY, Zhang S, Chen SY, Day AJ, et al. Biochemical characterization and function of complexes formed by hyaluronan and the heavy chains of inter-alpha-inhibitor ( $\mathrm{HC}^{*} \mathrm{HA}$ ) purified from extracts of human amniotic membrane. J Biol Chem. (2009) 284:20136-46. doi: 10.1074/jbc.M109.021881 the change in size of HA during inflammation also impacts AM survival, or its uptake by AMs, is also not known. During inflammation, AMs gain CD11b, but still retain high levels of CD11c and Siglec F, as well as their ability to bind HA, and are distinguishable from the newly differentiated monocyte-derived macrophages $\left(\mathrm{CD} 11 \mathrm{c}^{+}, \mathrm{CD}_{11} \mathrm{~b}^{+}\right.$, Siglec $\left.\mathrm{F}^{\mathrm{lo}}\right)$ that play a critical role in driving repair/fibrosis (12). The recovery of AM numbers during the repair phase suggests a function in the later stages of the response, perhaps in helping the return to homeostasis. With the resolution of inflammation and repair, monocyte-derived macrophages become phenotypically identical to tissue resident AMs, but they may not be functionally identical $(104,105)$.

In summary, HA levels are low in the alveolar space in the healthy lung, and HA bound to AMs promotes their survival. In the lung tissue, HA is present in the basement membranes of bronchioles and in the perivascular area. HA levels dramatically increase upon lung inflammation, perhaps enabling leukocytes to access the site of injury. Hyaladherins are also produced in response to inflammation and their interactions with HA can influence its physical properties and increase immune cell interactions. After repair and remodeling, HA levels eventually return to baseline, as inflammation is resolved. In situations of chronic disease, the persistence of HA is associated with increased inflammatory and fibrotic responses that are not resolved.

\section{ETHICS STATEMENT}

The figures were taken from work carried out in accordance with the guidelines for ethical animal research from the Canadian Council of Animal Care with protocols approved by the University of British Columbia Animal Care Committee.

\section{AUTHOR CONTRIBUTIONS}

PJ wrote the initial draft which was then worked on by all authors. AA provided the figures.

\section{ACKNOWLEDGMENTS}

The Natural Sciences and Engineering Research Council of Canada, the Cancer Research Society and the Canadian Institutes of Health Research (PJT-153455) provided financial support for our research. YD was supported by a University of British Columbia 4-year fellowship. 
7. Kopf M, Schneider C, Nobs SP. The development and function of lungresident macrophages and dendritic cells. Nat Immunol. (2015) 16:36-44. doi: $10.1038 /$ ni.3052

8. Culty M, Nguyen HA, Underhill CB. The hyaluronan receptor (CD44) participates in the uptake and degradation of hyaluronan. J Cell Biol. (1992) 116:1055-62. doi: 10.1083/jcb.116.4.1055

9. Culty M, O'Mara TE, Underhill CB, Yeager HJr, Swartz RP. Hyaluronan receptor (CD44) expression and function in human peripheral blood monocytes and alveolar macrophages. J Leukoc Biol. (1994) 56:605-11. doi: 10.1002/jlb.56.5.605

10. Green SJ, Tarone G, Underhill CB. Distribution of hyaluronate and hyaluronate receptors in the adult lung. J Cell Sci. (1988) 90: 145-56.

11. Cheng G, Swaidani S, Sharma M, Lauer ME, Hascall VC, Aronica MA. Hyaluronan deposition and correlation with inflammation in a murine ovalbumin model of asthma. Matrix Biol. (2011) 30:126-34. doi: 10.1016/j.matbio.2010.12.003

12. Dong Y, Poon GFT, Arif AA, Lee-Sayer SSM, Dosanjh M, Johnson P. The survival of fetal and bone marrow monocyte-derived alveolar macrophages is promoted by CD44 and its interaction with hyaluronan. Mucosal Immunol. (2018) 11:601-14. doi: 10.1038/mi.2017.83

13. Hussell T, Bell TJ. Alveolar macrophages: plasticity in a tissue-specific context. Nat Rev Immunol. (2014) 14:81-93. doi: 10.1038/nri3600

14. Sahu S, Lynn WS. Hyaluronic acid in the pulmonary secretions of patients with asthma. Biochem J. (1978) 173:565-8. doi: 10.1042/bj1730565

15. Fraser JR, Laurent TC, Laurent UB. Hyaluronan: its nature, distribution, functions and turnover. J Intern Med. (1997) 242:27-33. doi: 10.1046/j.1365-2796.1997.00170

16. Weigel PH, Deangelis PL. Hyaluronan synthases: a decade-plus of novel glycosyltransferases. J Biol Chem. (2007) 282:36777-81. doi: 10.1074/jbc.R700036200

17. Liang J, Zhang Y, Xie T, Liu N, Chen H, Geng Y, et al. Hyaluronan and TLR4 promote surfactant-protein-C-positive alveolar progenitor cell renewal and prevent severe pulmonary fibrosis in mice. Nat Med. (2016) 22:1285-93. doi: $10.1038 / \mathrm{nm} .4192$

18. Abbadi A, Lauer M, Swaidani S, Wang A, Hascall V. Hyaluronan rafts on airway epithelial cells. J Biol Chem. (2016) 291:1448-55. doi: 10.1074/jbc.M115.704288

19. Teder P, Vandivier RW, Jiang D, Liang J, Cohn L, Pure E, et al. Resolution of lung inflammation by CD44. Science (2002) 296:155-8. doi: 10.1126/science.1069659

20. Bourguignon V, Flamion B. Respective roles of hyaluronidases 1 and 2 in endogenous hyaluronan turnover. FASEB J. (2016) 30:2108-14. doi: 10.1096/fj.201500178R

21. Stern R, Jedrzejas MJ. Hyaluronidases: their genomics, structures, and mechanisms of action. Chem Rev. (2006) 106:818-39. doi: $10.1021 / \mathrm{cr} 050247 \mathrm{k}$

22. Yamaguchi Y, Yamamoto H, Tobisawa Y, Irie F. TMEM2: a missing link in hyaluronan catabolism identified? Matrix Biol. (2018). doi: 10.1016/j.matbio.2018.03.020. [Epub ahead of print]

23. Yoshida H, Nagaoka A, Kusaka-Kikushima A, Tobiishi M, Kawabata K, Sayo T, et al. KIAA1199, a deafness gene of unknown function, is a new hyaluronan binding protein involved in hyaluronan depolymerization. Proc Natl Acad Sci USA. (2013) 110:5612-7. doi: 10.1073/pnas.1215432110

24. Aya KL, Stern R. Hyaluronan in wound healing: rediscovering a major player. Wound Repair Regen. (2014) 22:579-93. doi: 10.1111/wrr.12214

25. Erickson M, Stern R. Chain gangs: new aspects of hyaluronan metabolism. Biochem Res Int. (2012) 2012:893947. doi: 10.1155/2012/893947

26. Lee-Sayer SS, Dong Y, Arif AA, Olsson M, Brown KL, Johnson P. The where, when, how, and why of hyaluronan binding by immune cells. Front Immunol. (2015) 6:150. doi: 10.3389/fimmu.2015.00150

27. Johnson P, Ruffell B. CD44 and its role in inflammation and inflammatory diseases. Inflamm Allergy Drug Targets (2009) 8:208-20. doi: $10.2174 / 187152809788680994$

28. Ruffell B, Johnson P. The Regulation and Function of Hyaluronan Binding by CD44 in the Immune System. Glycoforum: Science of hyaluronan today (2009). Available online at: www.glycoforum.gr.jp/science/hyaluronan/ HA32/HA32E.html
29. Pure E, Cuff CA. A crucial role for CD44 in inflammation. Trends Mol Med. (2001) 7:213-21. doi: 10.1016/S1471-4914(01)01963-3

30. Ponta H, Sherman L, Herrlich PA. CD44: from adhesion molecules to signalling regulators. Nat Rev Mol Cell Biol. (2003) 4:33-45. doi: $10.1038 / \mathrm{nrm} 1004$

31. Poon GF, Dong Y, Marshall KC, Arif A, Deeg CM, Dosanjh M, et al. Hyaluronan dinding identifies a functionally distinct alveolar macrophagelike population in bone marrow-derived dendritic cell cultures. J Immunol. (2015) 195:632-42. doi: 10.4049/jimmunol.1402506

32. Brown KL, Maiti A, Johnson P. Role of sulfation in CD44-mediated hyaluronan binding induced by inflammatory mediators in human CD14+ peripheral blood monocytes. J Immunol. (2001) 167:5367-74. doi: 10.4049/jimmunol.167.9.5367

33. Guilliams M, De Kleer I, Henri S, Post S, Vanhoutte L, De Prijck S, et al. Alveolar macrophages develop from fetal monocytes that differentiate into long-lived cells in the first week of life via GM-CSF. J Exp Med. (2013) 210:1977-92. doi: 10.1084/jem.20131199

34. Westphalen K, Gusarova GA, Islam MN, Subramanian M, Cohen TS, Prince AS, et al. Sessile alveolar macrophages communicate with alveolar epithelium to modulate immunity. Nature (2014) 506:503-6. doi: 10.1038/nature12902

35. Snelgrove RJ, Godlee A, Hussell T. Airway immune homeostasis and implications for influenza-induced inflammation. Trends Immunol. (2011). 32:328-34. doi: 10.1016/j.it.2011.04.006

36. Monslow J, Govindaraju P, Pure E. Hyaluronan - a functional and structural sweet spot in the tissue microenvironment. Front Immunol. (2015) 6:231. doi: 10.3389/fimmu.2015.00231

37. Bollyky PL, Lord JD, Masewicz SA, Evanko SP, Buckner JH, Wight TN, et al. Cutting Edge: High molecular weight hyaluronan promotes the suppressive effects of CD4+CD25+ regulatory T cells. J Immunol. (2007) 179:744-7. doi: 10.4049/jimmunol.179.2.744

38. Jiang D, Liang J, Fan J, Yu S, Chen S, Luo Y, et al. Regulation of lung injury and repair by Toll-like receptors and hyaluronan. Nat Med. (2005) 11:1173-9. doi: 10.1038/nm1315

39. Preston M, Sherman LS. Neural stem cell niches: roles for the hyaluronanbased extracellular matrix. Front Biosci. (2011) 3:1165-79. doi: 10.2741/218

40. Chanmee T, Ontong P, Kimata K, Itano N. Key roles of hyaluronan and its CD44 receptor in the stemness and survival of cancer stem cells. Front Oncol. (2015) 5:180. doi: 10.3389/fonc.2015.00180

41. Zoller M. CD44, Hyaluronan, the hematopoietic stem cell, and leukemiainitiating cells. Front Immunol. (2015) 6:235. doi: 10.3389/fimmu.2015.00235

42. Petrey AC, de la Motte CA. Hyaluronan, a crucial regulator of inflammation. Front Immunol. (2014) 5:101. doi: 10.3389/fimmu.2014.00101

43. Jiang D, Liang J, Noble PW. Hyaluronan as an immune regulator in human diseases. Physiol Rev. (2011) 91:221-64. doi: 10.1152/physrev.00052.2009

44. Lauer ME, Dweik RA, Garantziotis S, Aronica MA. The rise and fall of hyaluronan in respiratory diseases. Int J Cell Biol. (2015) 2015:712507. doi: $10.1155 / 2015 / 712507$

45. Lennon FE, Singleton PA. Role of hyaluronan and hyaluronan-binding proteins in lung pathobiology. Am J Physiol Lung Cell Mol Physiol. (2011) 301:L137-47. doi: 10.1152/ajplung.00071.2010

46. Wight TN, Frevert CW, Debley JS, Reeves SR, Parks WC, Ziegler SF. Interplay of extracellular matrix and leukocytes in lung inflammation. Cell Immunol. (2017) 312:1-14. doi: 10.1016/j.cellimm.2016.12.003

47. Jiang D, Liang J, Noble PW. Hyaluronan in tissue injury and repair. Annu Rev Cell Dev Biol. (2007) 23:435-61. doi: 10.1146/annurev.cellbio.23.090506.123337

48. Dentener MA. Enhanced levels of hyaluronan in lungs of patients with COPD: relationship with lung function and local inflammation. Thorax (2005) 60:114-9. doi: 10.1136/thx.2003.020842

49. Bjermer L, Lundgren R, Hallgren R. Hyaluronan and type III procollagen peptide concentrations in bronchoalveolar lavage fluid in idiopathic pulmonary fibrosis. Thorax (1989) 44:126-31.

50. Nettelbladt O, Hallgren R. Hyaluronan (hyaluronic acid) in bronchoalveolar lavage fluid during the development of bleomycin-induced alveolitis in the rat. Am Rev Respir Dis. (1989) 140:1028-32. doi: 10.1164/ajrccm/140. 4.1028

51. Cheng G, Swaidani S, Sharma M, Lauer ME, Hascall VC, Aronica MA. Correlation of hyaluronan deposition with infiltration of eosinophils and 
lymphocytes in a cockroach-induced murine model of asthma. Glycobiology (2013) 23:43-58. doi: 10.1093/glycob/cws122

52. Garantziotis S, Li Z, Potts EN, Kimata K, Zhuo L, Morgan DL, et al. Hyaluronan mediates ozone-induced airway hyperresponsiveness in mice. J Biol Chem (2009) 284:11309-17. doi: 10.1074/jbc.M802400200

53. Wang Q, Teder P, Judd NP, Noble PW, Doerschuk CM. CD44 deficiency leads to enhanced neutrophil migration and lung injury in Escherichia coli pneumonia in mice. Am J Pathol. (2002) 161:2219-28. doi: 10.1016/S0002-9440(10)64498-7

54. van der Windt GJ, Florquin S, de Vos AF, van't Veer C, Queiroz KC, Liang J, et al. CD44 deficiency is associated with increased bacterial clearance but enhanced lung inflammation during Gram-negative pneumonia. Am J Pathol. (2010) 177:2483-94. doi: 10.2353/ajpath.2010.1 00562

55. Bell TJ, Brand OJ, Morgan DJ, Salek-Ardakani S, Jagger C, Fujimori $\mathrm{T}$, et al. Defective lung function following influenza virus is due to prolonged, reversible hyaluronan synthesis. Matrix Biol. (2018). doi: 10.1016/j.matbio.2018.06.006. [Epub ahead of print].

56. Toole BP. Hyaluronan and its binding proteins, the hyaladherins. Curr Opin Cell Biol. (1990) 2:839-44. doi: 10.1016/0955-0674(90)90081-O

57. Day AJ, Prestwich GD. Hyaluronan-binding proteins: tying up the giant. $J$ Biol Chem. (2002) 277:4585-8. doi: 10.1074/jbc.R100036200

58. Wight TN, Kang I, Merrilees MJ. Versican and the control of inflammation. Matrix Biol. (2014) 35:152-61. doi: 10.1016/j.matbio.2014.01.015

59. Day AJ, Milner CM. TSG-6: a multifunctional protein with antiinflammatory and tissue-protective properties. Matrix Biol. (2018). doi: 10.1016/j.matbio.2018.01.011. [Epub ahead of print].

60. Tseng SC. HC-HA/PTX3 purified from amniotic membrane as novel regenerative matrix: insight into relationship between inflammation and regeneration. Invest Ophthalmol Vis Sci. (2016) 57:ORSFh1-8. doi: $10.1167 /$ iovs.15-17637

61. Baranova NS, Nileback E, Haller FM, Briggs DC, Svedhem S, Day AJ, et al. The inflammation-associated protein TSG-6 cross-links hyaluronan via hyaluronan-induced TSG-6 oligomers. J Biol Chem. (2011) 286:25675-86. doi: 10.1074/jbc.M111.247395

62. Lesley J, Gal I, Mahoney DJ, Cordell MR, Rugg MS, Hyman R, et al. TSG-6 modulates the interaction between hyaluronan and cell surface CD44. J Biol Chem. (2004) 279:25745-54. doi: 10.1074/jbc.M313319200

63. Petrey AC, de la Motte CA. Hyaluronan in inflammatory bowel disease: cross-linking inflammation and coagulation. Matrix Biol. (2018). doi: 10.1016/j.matbio.2018.03.011. [Epub ahead of print].

64. Albeiroti S, Ayasoufi K, Hill DR, Shen B, de la Motte CA. Platelet hyaluronidase-2: an enzyme that translocates to the surface upon activation to function in extracellular matrix degradation. Blood (2014) 125:1460-9. doi: 10.1182/blood-2014-07-590513

65. de la Motte C, Nigro J, Vasanji A, Rho H, Kessler S, Bandyopadhyay S, et al. Platelet-derived hyaluronidase 2 cleaves hyaluronan into fragments that trigger monocyte-mediated production of proinflammatory cytokines. Am J Pathol. (2009) 174:2254-64. doi: 10.2353/ajpath.2009.080831

66. Swaidani S, Cheng G, Lauer ME, Sharma M, Mikecz K, Hascall VC, et al. TSG-6 protein is crucial for the development of pulmonary hyaluronan deposition, eosinophilia, and airway hyperresponsiveness in a murine model of asthma. J Biol Chem. (2013) 288:412-22. doi: 10.1074/jbc.M112. 389874

67. Savani RC, Hou G, Liu P, Wang C, Simons E, Grimm PC, et al. A role for hyaluronan in macrophage accumulation and collagen deposition after bleomycin-induced lung injury. Am J Respir Cell Mol Biol. (2000) 23:475-84. doi: 10.1165/ajrcmb.23.4.3944

68. Maxwell CA, McCarthy J, Turley E. Cell-surface and mitotic-spindle RHAMM: moonlighting or dual oncogenic functions? J Cell Sci. (2008) 121:925-32. doi: $10.1242 /$ jcs. 022038

69. Connell M, Chen H, Jiang J, Kuan CW, Fotovati A, Chu TL, et al. HMMR acts in the PLK1-dependent spindle positioning pathway and supports neural development. Elife (2017) 6:28672. doi: 10.7554/eLife.28672

70. Tolg C, Poon R, Fodde R, Turley EA, Alman BA. Genetic deletion of receptor for hyaluronan-mediated motility (Rhamm) attenuates the formation of aggressive fibromatosis (desmoid tumor). Oncogene (2003) 22:6873-82. doi: 10.1038/sj.onc.1206811
71. Li H, Moll J, Winkler A, Frappart L, Brunet S, Hamann J, et al. RHAMM deficiency disrupts folliculogenesis resulting in female hypofertility. Biol Open (2015) 4:562-71. doi: 10.1242/bio.201410892

72. Cui Z, Liao J, Cheong N, Longoria C, Cao G, DeLisser HM, et al. The Receptor for Hyaluronan-Mediated Motility (CD168) promotes inflammation and fibrosis after acute lung injury. Matrix Biol. (2018). doi: 10.1016/j.matbio.2018.08.002. [Epub ahead of print].

73. Nettelbladt O, Tengblad A, Hallgren R. Lung accumulation of hyaluronan parallels pulmonary edema in experimental alveolitis. Am J Physiol. (1989) 257:L379-84. doi: 10.1152/ajplung.1989.257.6.L379

74. Huang Z, Zhao C, Chen Y, Cowell JA, Wei G, Kultti A, et al. Recombinant human hyaluronidase PH20 does not stimulate an acute inflammatory response and inhibits lipopolysaccharide-induced neutrophil recruitment in the air pouch model of inflammation. J Immunol. (2014) 192:5285-95. doi: 10.4049/jimmunol.1303060

75. Dong Y, Arif A, Olsson M, Cali V, Hardman B, Dosanjh M, et al. Endotoxin free hyaluronan and hyaluronan fragments do not stimulate TNF-alpha, interleukin-12 or upregulate co-stimulatory molecules in dendritic cells or macrophages. Sci Rep. (2016) 6:36928. doi: 10.1038/srep36928

76. Toole BP. Hyaluronan: from extracellular glue to pericellular cue. Nat Rev Cancer (2004) 4:528-39. doi: 10.1038/nrc1391

77. Gebe JA, Yadava K, Ruppert SM, Marshall P, Hill P, Falk BA, et al. Modified high-molecular-weight hyaluronan promotes allergen-specific immune tolerance. Am J Respir Cell Mol Biol. (2017) 56:109-20. doi: 10.1165/rcmb.2016-01110C

78. Weigel PH. Planning, evaluating and vetting receptor signaling studies to assess hyaluronan size-dependence and specificity. Glycobiology (2017) 27:796-9. doi: 10.1093/glycob/cwx056

79. Pandey MS, Baggenstoss BA, Washburn J, Harris EN, Weigel PH. The hyaluronan receptor for endocytosis (HARE) activates NFkappaB-mediated gene expression in response to $40-400-\mathrm{kDa}$, but not smaller or larger, hyaluronans. J Biol Chem. (2013) 288:14068-79. doi: 10.1074/jbc.M112.442889

80. Lesley J, Hascall VC, Tammi M, Hyman R. Hyaluronan binding by cell surface CD44. J Biol Chem. (2000) 275:26967-75. doi: 10.1074/jbc.M002527200

81. Weigel PH, Baggenstoss BA. What is special about $200 \mathrm{kDa}$ hyaluronan that activates hyaluronan receptor signaling? Glycobiology (2017) 27:868-77. doi: 10.1093/glycob/cwx039

82. Lawrance W, Banerji S, Day AJ, Bhattacharjee S, Jackson DG. Binding of hyaluronan to the native lymphatic vessel endothelial receptor LYVE-1 is critically dependent on receptor clustering and hyaluronan organization. $J$ Biol Chem. (2016) 291:8014-30. doi: 10.1074/jbc.M115.708305

83. Selbi W, de la Motte CA, Hascall VC, Day AJ, Bowen T, Phillips AO. Characterization of hyaluronan cable structure and function in renal proximal tubular epithelial cells. Kidney Int. (2006) 70:1287-95. doi: $10.1038 /$ sj.ki.5001760

84. Lee-Sayer SSM, Dougan MN, Cooper J, Sanderson L, Dosanjh M, Maxwell CA, et al. CD44-mediated hyaluronan binding marks proliferating hematopoietic progenitor cells and promotes bone marrow engraftment. PLoS ONE (2018) 13:e0196011. doi: 10.1371/journal.pone.0196011

85. Misharin AV, Morales-Nebreda L, Reyfman PA, Cuda CM, Walter JM, McQuattie-Pimentel AC, et al. Monocyte-derived alveolar macrophages drive lung fibrosis and persist in the lung over the life span. J Exp Med. (2017) 214:2387-404. doi: 10.1084/jem.20162152

86. Reeves SR, Kaber G, Sheih A, Cheng G, Aronica MA, Merrilees MJ, et al. Subepithelial accumulation of versican in a cockroach antigen-induced murine model of allergic asthma. J Histochem Cytochem. (2016) 64:364-80. doi: $10.1369 / 0022155416642989$

87. Westergren-Thorsson G, Särnstrand B, Fransson L- $\AA$, Malmström A. TGF- $\beta$ enhances the production of hyaluronan in human lung but not in skin fibroblasts. Exp Cell Res. (1990) 186:192-5. doi: 10.1016/0014-4827(90)90227-2

88. Midgley AC, Rogers M, Hallett MB, Clayton A, Bowen T, Phillips AO, et al. Transforming growth factor-betal (TGF-betal)-stimulated fibroblast to myofibroblast differentiation is mediated by hyaluronan (HA)-facilitated epidermal growth factor receptor (EGFR) and CD44 co-localization in lipid rafts. J Biol Chem. (2013) 288:14824-38. doi: 10.1074/jbc.M113.451336 
89. Webber J, Jenkins RH, Meran S, Phillips A, Steadman R. Modulation of TGFbetal-dependent myofibroblast differentiation by hyaluronan. Am J Pathol. (2009) 175:148-60. doi: 10.2353/ajpath.2009.080837

90. Meran S, Thomas D, Stephens P, Martin J, Bowen T, Phillips A, et al. Involvement of hyaluronan in regulation of fibroblast phenotype. $J$ Biol Chem. (2007) 282:25687-97. doi: 10.1074/jbc.M700773200

91. Stuhlmeier KM, Pollaschek C. Differential effect of transforming growth factor beta (TGF-beta) on the genes encoding hyaluronan synthases and utilization of the p38 MAPK pathway in TGF-beta-induced hyaluronan synthase 1 activation. J Biol Chem. (2004) 279:8753-60. doi: 10.1074/jbc.M303945200

92. Jenkins RH, Thomas GJ, Williams JD, Steadman R. Myofibroblastic differentiation leads to hyaluronan accumulation through reduced hyaluronan turnover. J Biol Chem. (2004) 279:41453-60. doi: 10.1074/jbc.M401678200

93. Meran S, Thomas DW, Stephens P, Enoch S, Martin J, Steadman R, et al. Hyaluronan facilitates transforming growth factor-beta1-mediated fibroblast proliferation. J Biol Chem. (2008) 283:6530-45. doi: 10.1074/jbc.M7048 19200

94. Meran S, Luo DD, Simpson R, Martin J, Wells A, Steadman R, et al. Hyaluronan facilitates transforming growth factor-betal-dependent proliferation via CD44 and epidermal growth factor receptor interaction. $J$ Biol Chem. (2011) 286:17618-30. doi: 10.1074/jbc.M111.226563

95. Martin J, Midgley A, Meran S, Woods E, Bowen T, Phillips AO, et al. Tumor necrosis factor-stimulated gene 6 (TSG-6)-mediated interactions with the inter-alpha-inhibitor heavy chain 5 facilitate tumor growth factor betal (TGFbeta1)-dependent fibroblast to myofibroblast differentiation. J Biol Chem. (2016) 291:13789-801. doi: 10.1074/jbc.M115. 670521

96. Li Y, Jiang D, Liang J, Meltzer EB, Gray A, Miura R, et al. Severe lung fibrosis requires an invasive fibroblast phenotype regulated by hyaluronan and CD44. J Exp Med. (2011) 208:1459-71. doi: 10.1084/jem.20102510

97. Li Y, Liang J, Yang T, Monterrosa Mena J, Huan C, Xie T, et al. Hyaluronan synthase 2 regulates fibroblast senescence in pulmonary fibrosis. Matrix Biol. (2016) 55:35-48. doi: 10.1016/j.matbio.2016.03.004

98. Hogan BL, Barkauskas CE, Chapman HA, Epstein JA, Jain R, Hsia CC, et al. Repair and regeneration of the respiratory system: complexity, plasticity, and mechanisms of lung stem cell function. Cell Stem Cell (2014) 15:123-38. doi: 10.1016/j.stem.2014.07.012
99. Maus UA, Janzen S, Wall G, Srivastava M, Blackwell TS, Christman JW, et al. Resident alveolar macrophages are replaced by recruited monocytes in response to endotoxin-induced lung inflammation. Am J Respir Cell Mol Biol. (2006) 35:227-35. doi: 10.1165/rcmb.2005-0241OC

100. Hashimoto D, Chow A, Noizat C, Teo P, Beasley MB, Leboeuf M, et al. Tissue-resident macrophages self-maintain locally throughout adult life with minimal contribution from circulating monocytes. Immunity (2013) 38:792804. doi: 10.1016/j.immuni.2013.04.004

101. Bleriot C, Dupuis T, Jouvion G, Eberl G, Disson O, Lecuit M. Liver-resident macrophage necroptosis orchestrates type 1 microbicidal inflammation and type-2-mediated tissue repair during bacterial infection. Immunity (2015) 42:145-58. doi: 10.1016/j.immuni.2014.12.020

102. Ginhoux F, Bleriot C, Lecuit M. Dying for a cause: regulated necrosis of tissue-resident macrophages upon infection. Trends Immunol. (2017) 38:693-5. doi: 10.1016/j.it.2017.05.009

103. Dagvadorj J, Shimada K, Chen S, Jones HD, Tumurkhuu G, Zhang W, et al. Lipopolysaccharide induces alveolar macrophage necrosis via CD14 and the $\mathrm{P} 2 \mathrm{X} 7$ receptor leading to interleukin-1alpha release. Immunity (2015) 42:640-53. doi: 10.1016/j.immuni.2015.03.007

104. Wong CK, Smith CA, Sakamoto K, Kaminski N, Koff JL, Goldstein DR. Aging impairs alveolar macrophage phagocytosis and increases influenza-induced mortality in mice. J Immunol. (2017) 199:1060-8. doi: 10.4049/jimmunol.1700397

105. Machiels B, Dourcy M, Xiao X, Javaux J, Mesnil C, Sabatel C, et al. A gammaherpesvirus provides protection against allergic asthma by inducing the replacement of resident alveolar macrophages with regulatory monocytes. Nat Immunol. (2017) 18:1310-20. doi: 10.1038/ni.3857

Conflict of Interest Statement: The authors declare that the research was conducted in the absence of any commercial or financial relationships that could be construed as a potential conflict of interest.

Copyright (C) 2018 Johnson, Arif, Lee-Sayer and Dong. This is an open-access article distributed under the terms of the Creative Commons Attribution License (CC BY). The use, distribution or reproduction in other forums is permitted, provided the original author(s) and the copyright owner(s) are credited and that the original publication in this journal is cited, in accordance with accepted academic practice. No use, distribution or reproduction is permitted which does not comply with these terms. 